\title{
ANALISIS COST-TO-SERVE DAN CUSTOMER PROFITABILITY DENGAN TIME-DRIVEN ACTIVITY-BASED COSTING
}

\author{
Edwina Meilani Hartono \\ Universitas Katolik Soegijapranata Semarang \\ edwinameilani@gmail.com
}

\begin{abstract}
ABSTRAK
Cost-to-serve adalah pendekatan yang paling penting bagi customer, produk, dan bagaimana mengelolanya dengan biaya yang sesuai. Cost-to-serve menargetkan aspek efisiensi, bauran produk, dan rasionalisasi dalam manajemen customer. Banyak entitas hanya menyadari pendapatan yang dihasilkan setiap customer dan tak mengetahui berapakah biaya yang dikeluarkan guna menjalin hubungan dengan customer. Penelitian ini menjembatani kesenjangan ini dengan mengidentifikasi penggunaan informasi cost-to serve dan analisis profitabilitas customer. Penelitian dilakukan dengan metode case study dan pendekatan kualitatif. Total cost-to-serve bisa didapatkan dengan mengalikan cost driver rate dan tingkat penggunaan aktivitas actual untuk tiap customer. Ada enam customer yang tidak menguntungkan atau menghasilkan customer loss dengan empat pabrik dan dua orang sesama distributor dengan rata-rata satu kali transaksi. Keputusan strategis mengenai pemilihan customer yang tepat bagi Quantum Sewtech Co., Ltd yaitu: (1) Menerapkan diferensiansi harga ketika sepi proyek karena penjualan Quantum Sewtech Co., Ltd bersifat musiman dan (2) Membuat kerjasama dengan ekspedisi untuk memaksimalkan penjualan ke luar kota karena strategi untuk melayani pembelian ke luar kota adalah strategi yang menguntungkan.
\end{abstract}

Kata Kunci: Cost-to-serve, customer profitability, time-driven activity-based costing

\section{PENDAHULUAN}

Cost-to-serve adalah pendekatan yang paling penting bagi customer, produk, dan bagaimana mengelolanya dengan biaya yang sesuai. Cost-to-serve menargetkan aspek efisiensi, bauran produk, dan rasionalisasi dalam manajemen customer. Manajemen secara rutin mencari informasi terperinci tentang biaya produksi produk perusahaan mereka, tetapi seringkali hanya memiliki sedikit gagasan tentang berapa biaya untuk melayani customer. Hal ini agak tidak sesuai, mengingat bahwa laba perusahaan seringkali tergantung pada customer cost-to-serve seperti halnya pada biaya produksi barang-barangnya. Dalam perusahaan jasa khususnya, profitabilitas per customer lebih penting daripada profitabilitas per produk. Namun, cost-to-serve seringkali tergantung pada perilaku customer, bukan dari supplier
(Guerreiro et al., 2008). Mengingat keadaan ini, banyak manajer melaporkan bahwa mereka memerlukan alat yang dapat diandalkan untuk menentukan efek biaya customer pada profitabilitas (Guerreiro et al., 2008).

Banyak entitas hanya menyadari pendapatan yang dihasilkan setiap customer dan tak mengetahui berapakah biaya yang dikeluarkan guna menjalin hubungan dengan customer. Biaya produk bisa diketahui untuk setiap customer tetapi biaya pemasaran dan penjualan serta jasa banyak diperlakukan sebagai biaya overhead. Maka, dibutuhkan metode alokasi biaya yang akurat agar profitabilitas customer bisa ditentukan secara tepat.

Studi kasus dari sebuah perusahaan makanan dengan berbagai produk dan jasa menunjukkan bahwa informasi cost-to serve 
dalam hal saluran penjualan penting untuk manajemen profitabilitas. Beberapa studi empiris telah benar-benar mengatasi masalah ini. Penelitian ini menjembatani kesenjangan ini dengan mengidentifikasi penggunaan informasi cost-to serve dan analisis profitabilitas customer. Hal ini dilakukan melalui studi kasus dari sebuah perusahaan industri garment Semarang dengan kompleksitas operasional yang tinggi dan produk yang luas. Di sektor ini, profitabilitas rendah, dan pengelolaan sumber daya yang terkait dengan cost-to serve dampak berdampak signifikan pada hasil bisnis.

Penelitian ini bertujuan mengidentifikasi cost-to serve kemudian menerapkan customer profitability analysis dengan time-driven activity-based costing pada Quantum Sewtech Co., Ltd, sebuah perusahaan retail perlengkapan industri garment seperti mesin jahit, sparepart mesin jahit, dan service mesin jahit yang berlokasi di kota Semarang. Quantum Sewtech Co. Ltd, dipilih sebagai objek penelitian dikarenakan perusahaan ini memiliki banyak aktivitas cost-to serve yang menyerap marjin laba kotor seperti adanya pengiriman lanjutan, customer yang membutuhkan jasa konsultasi, jasa pemasangan, entertainment, dan lain sebagainya.

\section{METODE PENELITIAN}

Penelitian dilakukan dengan metode case study dan pendekatan kualitatif. Farida (2016) mengemukakan case study sesuai dipakai utnuk pernyataan penelitian mengenai "why" dan "how". Penelitian case study bertujuan untuk mengembangkan dan/atau mengimplementasikan teori dengan mengidentifikasi fenomena dalam praktiknya. Penelitian ini bertujuan untuk mengidentifikasi customer cost-to-serve menggunakan time- driven activity-based costing, membuat customer profitability analysis, dan mengusulkan keputusan strategis yang tepat di Quantum Sewtech Co., Ltd, oleh karena itu pendekatan case study dirasa cocok untuk penelitian ini. Pendekatan kualitatif digunakan karena penelitian ini sangat memungkinkan untuk meneliti fokus permasalahan yang akan diteliti secara mendalam.

\section{HASIL DAN PEMBAHASAN}

Total Biaya Untuk Melayani Customer Tahun 2018 Menurut Time-Driven Activitybased Costing

Hasil perhitungan biaya untuk melayani customer tahun 2018 menunjukkan hanya Rp 1.206.965 atau 0,94\% dari total biaya $\mathrm{Rp}$ 128.774.781 yang dibebankan kepada customer karena total used capacity untuk aktivitas pelayanan di kantor hanya $\operatorname{Rp} 345.525(0,31 \%)$ sedangkan untuk aktivitas pengiriman hanya $\mathrm{Rp}$ 861.716 (4,66\%). Industri adalah customer dengan biaya pelayanan terbesar yakni sebesar Rp 1.118.978 atau 92,71\% dari total used capacity. Hal ini dikarenakan industri adalah kelompok customer terbanyak yang dilayani oleh Quantum Sewtech Co., Ltd tahun 2018 yakni 55 pabrik $(74,32 \%)$ dengan 41 pesanan baru dan 153 pesanan lanjutan. Rumah tangga adalah kelompok customer dengan biaya pengiriman terkecil yakni Rp 785 atau $0,07 \%$ dari total used capacity karena pesanan biasanya diambil sendiri atau dikirim langsung oleh supplier. Kelompok customer dengan biaya pelayanan di kantor paling kecil yaitu rumah tangga yakni Rp 8.667 atau 0,72\% dari total used capacity karena rumah tangga menghasilkan penjualan terkecil tahun 2018 yakni $\mathrm{Rp} 19.739 .800$ atau $1,03 \%$ dari total penjualan tahun 2018. 
Tabel 1 Total Biaya Untuk Melayani Customer Tahun 2018 Menurut Time-Driven Activity-based Costing

\begin{tabular}{|c|c|c|c|c|c|c|c|c|c|c|c|c|c|}
\hline \multirow{2}{*}{ NO } & \multirow{2}{*}{ AKTIVITAS } & \multicolumn{3}{|c|}{ KUANTITAS } & \multicolumn{2}{|c|}{ UNIT TIME } & \multicolumn{3}{|c|}{$\begin{array}{c}\text { TOTAL WAKTU } \\
(\text { MENIT) }\end{array}$} & \multirow{2}{*}{$\begin{array}{l}\text { COST } \\
\text { RATE }\end{array}$} & \multicolumn{3}{|c|}{ TOTAL BIAYA (RUPIAH) } \\
\hline & & RT & IN & SD & RT & IN & RT & IN & SD & & $\mathbf{R T}$ & IN & SD \\
\hline 1. a. & $\begin{array}{l}\text { Untuk pesanan baru: } \\
\text { Menjawab pertanyaan } \\
\text { customer dan } \\
\text { merekomendasikan } \\
\text { produk } \\
\text { yang sesuai }\end{array}$ & 8 & 41 & 15 & 10 & 5 & 80 & 205 & 75 & 57 & 4,560 & 11,685 & 4,275 \\
\hline 1. b. & $\begin{array}{l}\text { Untuk pesanan } \\
\text { lanjutan: Menerima } \\
\text { pesanan dari customer } \\
\text { dan mencari data } \\
\text { customer }\end{array}$ & 2 & 153 & 3 & & 3 & 6 & 459 & 9 & 57 & 342 & 26,163 & 513 \\
\hline \multirow{2}{*}{2} & $\begin{array}{l}\text { Membuat invoice dan } \\
\text { menerima } \\
\text { pembayaran (pesanan } \\
\text { baru) }\end{array}$ & 8 & 41 & 15 & & 5 & 40 & 205 & 75 & 57 & 2,280 & 11,685 & 4,275 \\
\hline & $\begin{array}{l}\text { Membuat invoice dan } \\
\text { menerima } \\
\text { pembayaran (pesanan } \\
\text { lanjutan) }\end{array}$ & 2 & 153 & 3 & & 2 & 4 & 306 & 6 & 57 & 228 & 17,442 & 342 \\
\hline \multirow[t]{2}{*}{ 3. a. } & $\begin{array}{l}\text { Apabila pesanan } \\
\text { dikirim langsung oleh } \\
\text { supplier: } \\
\text { 3. a. (i) Mengirimkan } \\
\text { surat pesanan melalui } \\
\text { telepon atau e-mail dan } \\
\text { mengkonfirmasi } \\
\text { pesanan }\end{array}$ & 0 & 10 & 10 & & 4 & 0 & 40 & 40 & 57 & 0 & 2,280 & 2,280 \\
\hline & $\begin{array}{l}\text { 3. a. (iii) Pengecekan } \\
\text { surat jalan yang } \\
\text { dikirim supplier }\end{array}$ & 0 & 10 & 10 & & 1 & 0 & 10 & 10 & 57 & 0 & 570 & 570 \\
\hline 3. c. (i) & $\begin{array}{l}\text { Membuat surat jalan } \\
\text { (apabila barang dikirim } \\
\text { dengan kendaraan } \\
\text { Quantum Sewtech Co., } \\
\text { Ltd }\end{array}$ & 0 & 136 & 19 & & 2 & 0 & 272 & 38 & 57 & 0 & 15,504 & 2,166 \\
\hline $\begin{array}{l}\text { 3. b. (i) } \\
\text { atau } \\
\text { 3. c. (ii) }\end{array}$ & $\begin{array}{l}\text { Muat barang ke } \\
\text { kendaraan pengiriman } \\
\text { (apabila barang dikirim } \\
\text { dengan kendaraan } \\
\text { Quantum Sewtech Co., } \\
\text { Ltd) atau ke } \\
\text { kendaraan customer } \\
\text { (apabila barang diambil } \\
\text { sendiri oleh } \text { customer) }\end{array}$ & \multicolumn{5}{|c|}{ Bergantung jenis barang, lihat Tabel 4.9} & 11 & 3,344 & 74 & 57 & 640 & 190,626 & 4,197 \\
\hline $\begin{array}{l}\text { 3. b. (ii) } \\
\text { atau } \\
\text { 3. c. (iii) }\end{array}$ & $\begin{array}{l}\text { Menghitung, mengecek } \\
\text { ketepatan jumlah, } \\
\text { dan jenis barang } \\
\text { (apabila barang diambil } \\
\text { sendiri atau dikirim } \\
\text { dengan kendaraan } \\
\text { Quantum Sewtech Co., } \\
\text { Ltd) }\end{array}$ & 84 & 42,580 & 924 & \multicolumn{2}{|r|}{0.01} & 1 & 426 & 9 & 57 & 48 & 24,271 & 527 \\
\hline 3. b. (iii) & $\begin{array}{l}\text { Membuat tanda terima } \\
\text { (apabila barang } \\
\text { diambil sendiri) }\end{array}$ & 0 & 13 & 32 & \multicolumn{2}{|r|}{2} & 0 & 26 & 64 & 57 & 0 & 1,482 & 3,648 \\
\hline 3. c. (iv) & $\begin{array}{l}\text { Mengendarai } \\
\text { kendaraan ke tempat } \\
\text { pembeli } \\
\text { (apabila barang dikirim } \\
\text { dengan kendaraan } \\
\text { Quantum Sewtech Co., }\end{array}$ & \multicolumn{5}{|c|}{$\begin{array}{l}\text { Bergantung jarak tempat dari kantor Quantum } \\
\text { Sewtech Co., Ltd yang ditentukan melalui Google } \\
\text { Maps ditambah } 5 \text { menit untuk mencari tempat } \\
\text { pertama pada pengiriman pertama }\end{array}$} & 0 & 7,765 & 651 & 70 & 0 & 543,550 & 45,570 \\
\hline
\end{tabular}




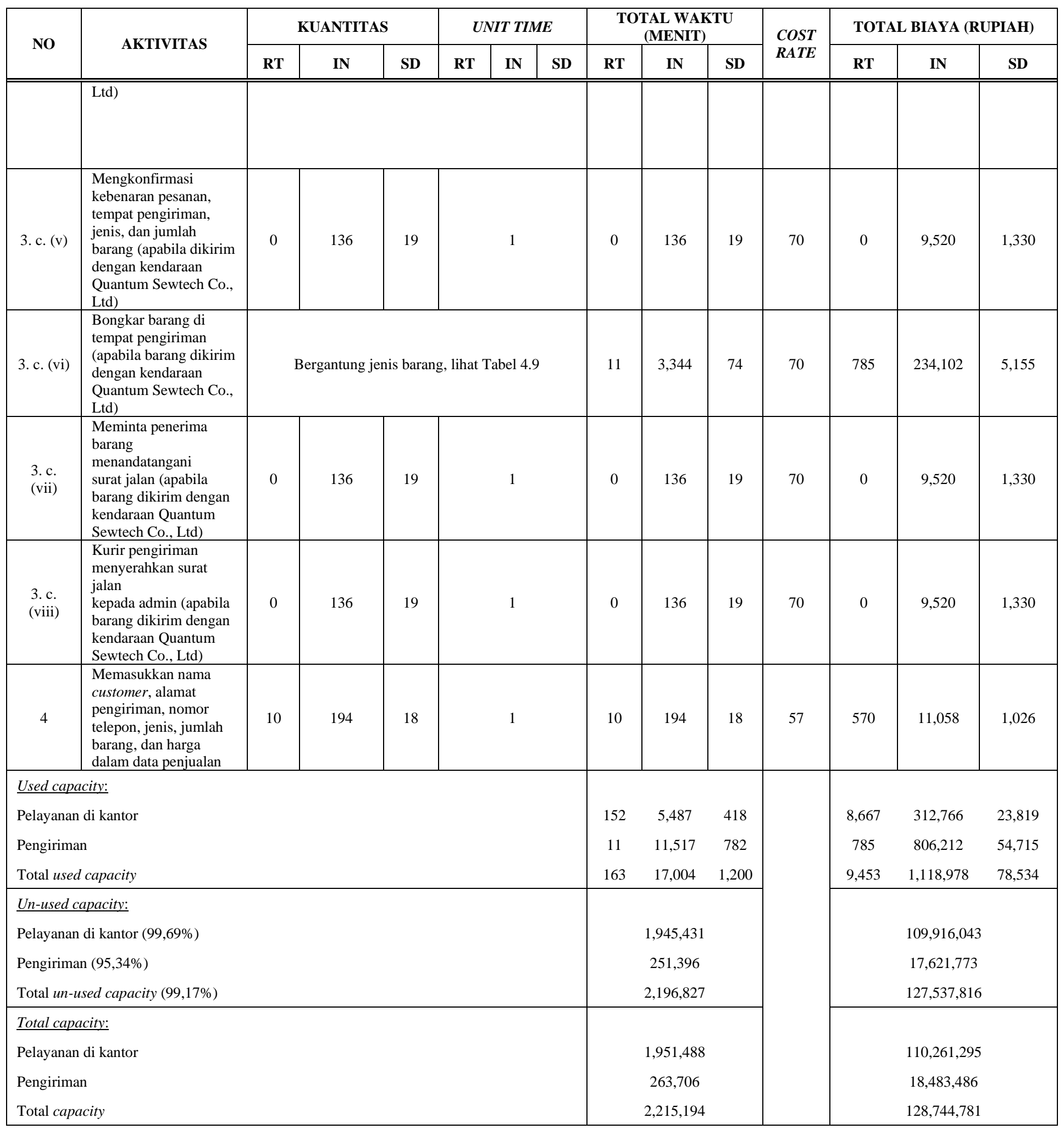

Sumber: Data Quantum Sewtech Co., Ltd yang sudah diolah

Keterangan: $\mathrm{RT}=$ rumah tangga, $\mathrm{IN}=$ industri, $\mathrm{SD}=$ sesama distributor 


\section{Perhitungan Customer Profitability}

Customer yang memerlukan biaya pelayanan paling besar yaitu sesama distributor yakni $1,60 \%$ dari penjualan. Customer Quantum Sewtech Co., Ltd terbanyak oleh industri yakni sebanyak $75,68 \%$ atau 56 pabrik sehingga customer profit paling besar didapatkan oleh customer dalam kelompok ini yakni Rp 278.105.915 atau 97,57\% dari total customer profit. Industri memerlukan biaya pelayanan $0,51 \%$ dari penjualan dan dapat menghasilkan customer profit margin sebesar $15,06 \%$. Customer dengan biaya pelayanan terkecil yaitu rumah tangga yakni $0,07 \%$ dari penjuaan dan hanya dapat menghasilkan customer profit margin $9,75 \%$ dari penjualan. Sesama distributor hanya menghasilkan laba bersih Rp 5.006.939 atau $1,76 \%$ dai total customer profit.

Tabel 2 Customer Profitability Report Quantum Sewtech Co., Ltd Tahun 2018

\begin{tabular}{|l|r|r|r|r|}
\hline \multirow{2}{*}{ KETERANGAN } & \multicolumn{3}{|c|}{ JENIS CUSTOMER } & \multirow{2}{*}{ TOTAL } \\
\cline { 2 - 5 } & \multicolumn{1}{|c|}{$\begin{array}{c}\text { RUMAH } \\
\text { TANGGA }\end{array}$} & \multicolumn{1}{c|}{ INDUSTRI } & $\begin{array}{c}\text { SESAMA } \\
\text { DISTRIBUTOR }\end{array}$ & \\
\hline \hline Penjualan & $19,739,800$ & $1,846,348,810$ & $51,359,400$ & $1,917,448,010$ \\
\hline Harga pokok penjualan & $17,802,220$ & $1,558,848,384$ & $45,532,010$ & $1,622,182,614$ \\
\hline Laba kotor & $1,937,580$ & $287,500,426$ & $5,827,390$ & $295,265,396$ \\
\hline Biaya pelayanan: & & & & \\
Biaya pelayanan di kantor & 8,667 & 312,766 & 23,819 & 345,252 \\
Biaya pengiriman & 785 & 806,212 & 54,715 & 861,713 \\
Biaya invoice & 2,600 & 38,200 & 3,600 & 44,400 \\
Biaya surat jalan atau tanda terima & 1,560 & 22,920 & 2,700 & 27,180 \\
Biaya bensin & 0 & $8,214,413$ & 735,617 & $8,950,030$ \\
Total biaya pelayanan & 13,613 & $9,394,511$ & 820,451 & $10,228,575$ \\
\hline Customer profit & $1,923,967$ & $278,105,915$ & $5,006,939$ & $285,036,821$ \\
\hline Jumlah customer & 11 & 56 & & 7 \\
\hline Biaya pelayanan & $9.07 \%$ & $0.51 \%$ & $1.60 \%$ & $2.18 \%$ \\
\hline Customer profit margin & $9.75 \%$ & $15.06 \%$ & $9.75 \%$ & $34.56 \%$ \\
\hline
\end{tabular}

Sumber: Data Quantum Sewtech Co., Ltd yang sudah diolah

Tabel 2 memperlihatkan customer profit (loss) tahun 2018 berkisar ( $R p$ 481.873) sampai Rp 22.973.580. Enam customer mendapatkan customer loss dengan empat customer adalah industri dan dua customer adalah sesama distributor. 33 customer $(44,60 \%)$ mendapatkan customer profit antara $\mathrm{Rp} 0$ sampai Rp 1.000.000. Customer profit terbesar yakni $\mathrm{Rp}$ 22.973.580 didapatkan oleh industri yang melakukan empat pesaman selama tahun 2018 sedangkan customer loss terbesar Rp 481.873 didapatkan oleh sesama distributor yang hanya melakukan satu kali pesanan. Dari tiga kelompok customer hanya rumah tangga yang $100 \%$ mendapatkan customer profit. Hal ini diperlihatkan dari customer profit minimum rumah tangga sebesar Rp 33.425.

Tabel 3 Rincian Customer Profit (Loss) Quantum Sewtech Co., Ltd Tahun 2018

\begin{tabular}{|r|r|r|r|r|}
\hline \multirow{2}{*}{$\begin{array}{c}\text { CUSTOMER } \\
\text { PROFIT (LOSS) }\end{array}$} & \multicolumn{3}{|c|}{ JUMLAH CUSTOMER } & \multirow{2}{*}{ TOTAL } \\
\cline { 2 - 5 } & $\begin{array}{c}\text { RUMAH } \\
\text { TANGGA }\end{array}$ & INDUSTRI & $\begin{array}{c}\text { SESAMA } \\
\text { DISTRIBUTOR }\end{array}$ & \\
\hline \hline$<0$ & 0 & 4 & 2 & 6 \\
\hline $0-1.000 .000$ & 11 & 19 & 3 & 33 \\
\hline $1.000 .001-2.000 .000$ & 0 & 7 & 1 & 8 \\
\hline
\end{tabular}




\begin{tabular}{|l|r|r|r|r|}
\hline $2.000 .001-3.000 .000$ & 0 & 6 & 1 & 7 \\
\hline $3.000 .001-4.000 .000$ & 0 & 1 & 0 & 1 \\
\hline $4.000 .001-5.000 .000$ & 0 & 0 & 0 & 0 \\
\hline $5.000 .001-6.000 .000$ & 0 & 4 & 0 & 4 \\
\hline $6.000 .001-7.000 .000$ & 0 & 1 & 0 & 2 \\
\hline $7.000 .001-8.000 .000$ & 0 & 0 & 0 & 0 \\
\hline $8.000 .001-9.000 .000$ & 0 & 12 & 0 & 12 \\
\hline$>9.000 .000$ & 11 & 56 & 7 & 74 \\
\hline $\begin{array}{l}\text { Total } \\
\text { maksimum }\end{array}$ & 429,264 & $22,973,580$ & $2,739,897$ & \\
\hline $\begin{array}{l}\text { Customer profit (loss) } \\
\text { minimum }\end{array}$ & 33,425 & $-67,298$ & $-481,873$ & \\
\hline
\end{tabular}

Sumber: Data Quantum Sewtech Co., Ltd yang sudah diolah

\section{Identifikasi Customer Yang Menguntungkan}

\section{dan Tidak}

Setelah mendapatkan customer profit (loss) masing-masing customer, customer bisa dikelompokkan menjadi dua yakni customer yang menguntungkan, dan tidak menguntungkan. Hasil pengelompokkan bisa ditunjukkan di Tabel 4

Tabel 5 Rincian Customer Yang Tidak Menguntungkan

\begin{tabular}{|c|c|c|c|c|c|c|c|}
\hline $\begin{array}{c}\text { JENIS } \\
\text { CUSTOMER }\end{array}$ & $\begin{array}{c}\text { NOMOR } \\
\text { CUSTOMER }\end{array}$ & PENDAPATAN & $\begin{array}{c}\text { HARGA } \\
\text { POKOK } \\
\text { PENJUALAN }\end{array}$ & $\begin{array}{c}\text { GROSS } \\
\text { PROFIT }\end{array}$ & $\begin{array}{c}\text { COST- } \\
\text { TO- } \\
\text { SERVE }\end{array}$ & $\begin{array}{c}\text { CUSTOMER } \\
\text { PROFIT } \\
\text { (LOSS) }\end{array}$ & $\begin{array}{c}\text { JUMLAH } \\
\text { TRANSAKSI }\end{array}$ \\
\hline $\begin{array}{l}\text { Sesama } \\
\text { distributor }\end{array}$ & 48 & $\mathrm{Rp} \quad 286,000$ & Rp $\quad 220,000$ & $\mathrm{Rp} \quad 66,000$ & 143,375 & $-77,375$ & 1 \\
\hline Industri & 104 & $\mathrm{Rp} \quad 200,000$ & Rp $\quad 100,000$ & Rp 100,000 & 167,298 & $-67,298$ & 1 \\
\hline Industri & 117 & Rp $1,380,000$ & Rp 1,140,480 & Rp 239,520 & 289,452 & $-49,932$ & 1 \\
\hline Industri & 167 & 45,000 & 35,000 & $\mathrm{Rp} \quad 10,000$ & 13,308 & $-3,308$ & 1 \\
\hline $\begin{array}{l}\text { Sesama } \\
\text { distributor }\end{array}$ & 215 & Rp $1,900,000$ & $\operatorname{Rp} 1,750,140$ & Rp 149,860 & 631,733 & $-481,873$ & 1 \\
\hline Industri & 217 & $\mathrm{Rp} \quad 611,400$ & $\mathrm{Rp} \quad 462,773$ & Rp 148,627 & 156,582 & $-7,955$ & 1 \\
\hline
\end{tabular}

Sumber: Data Quantum Sewtech Co., Ltd yang sudah diolah

Analisis lebih dalam terhadap customer yang ada di Tabel 5 menunjukkan penyebab customer tersebut tidak menguntungkan yaitu gross profit tidak bisa menutupi biaya pelayanan karena marjin laba produk yang dibeli terlalu kecil. Deskripsi jenis produk, harga pokok penjualan, marjin laba, dan harga
Tabel 4 Jumlah Customer Yang Menguntungkan dan Tidak Berdasarkan Kelompok

\begin{tabular}{|l|r|r|r|}
\hline \multirow{2}{*}{ JENIS CUSTOMER } & \multicolumn{3}{|c|}{ JUMLAH CUSTOMER (ORANG) } \\
\cline { 2 - 4 } & MENGUNTUNGKAN & $\begin{array}{c}\text { TIDAK } \\
\text { MENGUNTUNGKAN }\end{array}$ & TOTAL \\
\hline \hline Rumah tangga & 11 & 0 & 11 \\
\hline Industri & 52 & 4 & 56 \\
\hline Sesama distributor & 5 & 2 & 7 \\
\hline Total & 68 & 6 & 74 \\
\hline
\end{tabular}

Sumber: Data Quantum Sewtech Co., Ltd yang sudah diolah

Hasil memperlihatkan ada enam customer yang tidak menguntungkan atau menghasilkan customer loss dengan empat pabrik dan dua orang sesama distributor dengan rata-rata satu kali transaksi. Deskripsi customer yang termasuk dalam kelompok customer yang tidak menguntungkan bisa dilihat di Tabel 5. 


\begin{tabular}{|c|c|c|c|c|}
\hline JENIS PRODUK & HARGA JUAL & & $\begin{array}{l}\text { GA POKOK } \\
\text { JJUALAN } \\
\end{array}$ & $\begin{array}{c}\text { MARJIN } \\
\text { LABA } \\
\end{array}$ \\
\hline Sparepart ukuran kecil & $\mathrm{Rp} \quad 286,000$ & $\mathrm{Rp}$ & 220,000 & $23.08 \%$ \\
\hline Sparepart ukuran kecil & $\mathrm{Rp} \quad 200,000$ & $\mathrm{Rp}$ & 100,000 & $50.00 \%$ \\
\hline Sparepart ukuran besar & Rp $1,380,000$ & $\mathrm{Rp}$ & $1,140,480$ & $17.36 \%$ \\
\hline Sparepart ukuran besar & 45,000 & $\mathrm{Rp}$ & 35,000 & $22.22 \%$ \\
\hline Mesin ukuran kecil & Rp $1,900,000$ & $\mathrm{Rp}$ & $1,750,140$ & $7.89 \%$ \\
\hline Sparepart ukuran kecil & $\mathrm{Rp} \quad 611,400$ & $\mathrm{Rp}$ & 462,773 & $24.31 \%$ \\
\hline
\end{tabular}

Sumber: Data Quantum Sewtech Co., Ltd yang sudah diolah
Marjin laba produk yang menyebabkan kerugian berkisar $7,89 \%$ sampai $50,00 \%$ dari harga jual. Selain mengidentifikasi customer yang tidak menguntungkan, butuh dilakukan identifikasi customer yang paling menguntungkan untuk melihat pola pembelian dari customer tersebut, dan menentukan strategi yang bisa meningkatkan profitabilitas customer. Rincian sepuluh customer yang paling menguntungkan dari customer profit di Tabel 7 menunjukkan semua customer paling menguntungkan yaitu industri.

Tabel 7 Rincian Sepuluh Customer Yang Paling Menguntungkan

\begin{tabular}{|c|c|c|c|c|c|c|c|c|c|c|c|}
\hline $\begin{array}{c}\text { JENIS } \\
\text { CUSTOMER }\end{array}$ & $\begin{array}{c}\text { NOMOR } \\
\text { CUSTOMER }\end{array}$ & \multicolumn{2}{|c|}{ PENDAPATAN } & \multicolumn{2}{|c|}{$\begin{array}{c}\text { HARGA } \\
\text { POKOK } \\
\text { PENJUALAN }\end{array}$} & \multicolumn{2}{|c|}{$\begin{array}{c}\text { GROSS } \\
\text { PROFIT }\end{array}$} & \multirow{2}{*}{$\begin{array}{c}\text { COST- } \\
\text { TO- } \\
\text { SERVE }\end{array}$} & \multicolumn{2}{|c|}{$\begin{array}{c}\text { CUSTOMER } \\
\text { PROFIT }\end{array}$} & $\begin{array}{l}\text { JUMLAH } \\
\text { PESANAN }\end{array}$ \\
\hline Industri & 4 & $\mathrm{Rp}$ & $13,432,000$ & $\mathrm{Rp}$ & $8,592,140$ & $\mathrm{Rp}$ & $4,839,860$ & & $\mathrm{Rp}$ & $4,815,904$ & 8 \\
\hline Industri & 12 & $\mathrm{Rp}$ & $3,000,000$ & $\mathrm{Rp}$ & $2,100,000$ & $\mathrm{Rp}$ & 900,000 & 14,837 & $\mathrm{Rp}$ & 885,163 & 7 \\
\hline Industri & 40 & $\mathrm{Rp}$ & $2,339,000$ & $\mathrm{Rp}$ & $1,743,273$ & $\mathrm{Rp}$ & 595,727 & 170,949 & $\mathrm{Rp}$ & 424,778 & 4 \\
\hline Industri & 52 & $\mathrm{Rp}$ & $328,500,000$ & $\mathrm{Rp}$ & $12,075,000$ & $\mathrm{Rp}$ & $6,425,000$ & 17,469 & $\mathrm{Rp}$ & $6,407,531$ & 1 \\
\hline Industri & 63 & $\mathrm{Rp}$ & $14,084,000$ & $\mathrm{Rp}$ & $9,451,800$ & $\mathrm{Rp}$ & $4,632,200$ & 12,700 & $\mathrm{Rp}$ & $4,619,500$ & 8 \\
\hline Industri & 71 & $\mathrm{Rp}$ & $13,182,400$ & $\mathrm{Rp}$ & $11,042,096$ & $\mathrm{Rp}$ & $2,140,304$ & 52,114 & $\mathrm{Rp}$ & $2,088,190$ & 10 \\
\hline Industri & 82 & $\mathrm{Rp}$ & $1,953,800$ & $\mathrm{Rp}$ & $1,407,194$ & $\mathrm{Rp}$ & 546,606 & 1,587 & $\mathrm{Rp}$ & 545,019 & 11 \\
\hline Industri & 134 & $\mathrm{Rp}$ & $1,750,000$ & $\mathrm{Rp}$ & $1,300,000$ & $\mathrm{Rp}$ & 450,000 & 9,618 & $\mathrm{Rp}$ & 440,382 & 11 \\
\hline Industri & 148 & $\mathrm{Rp}$ & $32,134,700$ & $\mathrm{Rp}$ & $19,459,355$ & $\mathrm{Rp}$ & $2,675,345$ & 45,587 & & $2,629,758$ & 2 \\
\hline Industri & 185 & $\mathrm{Rp}$ & $2,200,000$ & $\mathrm{Rp}$ & $1,900,000$ & $\mathrm{Rp}$ & 300,000 & 52,322 & $\mathrm{Rp}$ & 247,678 & 10 \\
\hline
\end{tabular}

Sumber: Data Quantum Sewtech Co., Ltd yang sudah diolah

Rata-rata pesanan industri yaitu tujuh pesanan tiap customer. Analisis lebih lanjut terhadap sepuluh customer paling menguntungkan menunjukkan customer profit customer ini berkisar 5\% sampai 39\% dari penjualan. Customer industri nomor 52 hanya menghasilkan customer profit 55\% dari penjualan.

\section{KESIMPULAN}

Ada enam customer yang tidak menguntungkan atau menghasilkan customer loss dengan empat pabrik dan dua orang sesama distributor dengan rata-rata satu kali transaksi. Keputusan strategis mengenai pemilihan customer yang tepat bagi Quantum Sewtech Co., Ltd yaitu: (1) Menerapkan diferensiansi harga ketika sepi proyek karena penjualan Quantum Sewtech Co., Ltd bersifat musiman dan (2) Membuat kerjasama dengan ekspedisi untuk memaksimalkan penjualan ke luar kota karena strategi untuk melayani pembelian ke luar kota adalah strategi yang menguntungkan.

\section{DAFTAR PUSTAKA}

Adelia, \& Setiawan, J. (2011). Implementasi Customer Relationship Management ( Crm 
) Pada Sistem Reservasi Hotel Berbasis Website Dan Desktop, 113-126. Retrieved From

Https://Media.Neliti.Com/Media/Publicati ons/219482-Implementasi-Customer-

Relationship-Manag.Pdf

Adnin, R. J., Lubis, N., \& Widayanto. (2013). Pengaruh Customer Relationship Management Terhadap Loyalitas Pelanggan Pt. Nasmoco Pemuda Semarang, 1-8. Retrieved From Https://Ejournal.Unsrat.Ac.Id/Index.Php/E mba/Article/View/2960/2506

Azmi, Z. (2018). Time Driven Activity Based Costing Dan Implementasinya Pada Jasa Perawatan Kesehatan. Retrieved From File:///D:/Data/Downloads/736-73-1037-110-20180618.Pdfs

Dalci, I. (2017). Customer Profitability Analysis With Time-Driven ActivityBased Customer Profitability Analysis With Time-Driven Activity-Based Costing: A Case Study In A Hotel, (July). Https://Doi.Org/10.1108/09596111011053 774

Dirvi Surya Abbas, Arry Eksandy. (2020). The Effect Of Effective Tax Rate, Tunneling Incentive, And Exchange Rate On Company Decisions To Transfer Pricing : Food And Consumption Sub-Sector Companies Listed On The Indonesia Evidence. Palarch's Journal Of Archaeology Of Egypt / Egyptology, 17(7), 14430-14442. Retrieved From Https://Archives.Palarch.N1/Index.Php/Jae/Art icle/View/5486

Everaert, P., Bruggeman, W., \& Creus, G. De. (2008). Sanac Inc.: From Abc To TimeDriven Abc (Tdabc ) - An Instructional Case.

Https://Doi.Org/10.1016/J.Jaccedu.2008.0 3.001

Farida, A. (2016). Customer Profitability Analysis Dengan Time-Driven ActivityBased-Costing: Studi Kasus Pada Jaya Genteng. Surabaya. Retrieved From Http://Repository.Unair.Ac.Id/55433/13/F aridaariyani_Tesis_-Min.Pdf
Freitas, V. D. O. P. R. De. (2017). Cost-ToServe Analysis A Case Study In A Fmcg Company, (October), 1-11. Retrieved From

Https://Fenix.Tecnico.Ulisboa.Pt/Downloa dfile/1126295043835415/Extended

Abstract _ Analise Cost To Serve.Pdf

Guerreiro, R., Rodrigues Bio, S., \& Vazquez Villamor Merschmann, E. (2008). CostTo-Serve Measurement And Customer Profitability Analysis. The International Journal Of Logistics Management, 19(3), 389-407.

Https://Doi.Org/10.1108/09574090810919 215

Hariyati. (2011). Time Driven Activity-Based Costing: Konsep Akuntansi Manajemen Yang Akurat Dalam Menghadapi Lingkungan Yang Dinamis Dan Bisnis Global, 2(031). Retrieved From File:///D:/Data/Downloads/Time_Driven_ Activity-

Based_Costing_Konsep_Akuntans.Pdf

Hezczkova, M., \& Stoklasa, M. (2011). Customer Relationship Management Theory And Principles, 80-91. Retrieved From

Https://Pdfs.Semanticscholar.Org/8096/Cf

78a7d01aad1eddbb34d0c6dec30e20bc40.P df?_Ga=2.73919185.294089185.15665579 27-1725440466.1566557927

Kalalo, R. E. (2013). Customer Relationship Management Dan Kualitas Pelayanan Pengaruhnya Terhadap Loyalitas Konsumen Pt. Matahari Dept. Store, Manado, 1(4), 1553-1561. Retrieved From Https://Ejournal.Unsrat.Ac.Id/Index.Php/E $\mathrm{mba} /$ Article/View/2960/2506

Li, W. S. (2018). Strategic Management Accounting.

Mugunthan, C., \& Kalaiarasi, G. (2017). Theoretical Framework Of Customer Relationship Management: An Overview, 5(07), 6431-6441. Https://Doi.Org/10.18535/Ijsrm/V5i7.78

Niraj, R., Foster, G., Gupta, M., \& Narasimhan, 
C. (2003). Understanding Customer Level Profitability Implications of Satisfaction Programs.

Https://Doi.Org/10.1108/08858620810901 211

Parkhi, S., Patil, S., \& Sharma, A. (2017). CostTo-Serve: A Strategic Tool For Decision Making In Hotel Industry Using Fuzzy Technique. International Journal of Services And Operations Management,
26(4),

476-497. Https://Doi.Org/10.1504/Ijsom.2017.0828 94

Zailani, A. (2009). Pengukuran Kinerja Perusahaan Dengan Balanced Scorecard, 67-81. Retrieved From Http://Www.Jp.Feb.Unsoed.Ac.Id/Index.P hp/Performance/Article/Viewfile/30/35 